\title{
Buoyancy does not affect diving metabolism during shallow dives in Steller sea lions Eumetopias jubatus
}

\author{
A. Fahlman ${ }^{1, *}$, G. D. Hastie ${ }^{1,3}$, D. A. S. Rosen ${ }^{1}$, Y. Naito ${ }^{2}$, A. W. Trites ${ }^{1}$ \\ ${ }^{1}$ Marine Mammal Research Unit, Fisheries Centre, Room 247, AERL-Aquatic Ecosystems Research Laboratory, \\ University of British Columbia, Vancouver, British Columbia V6T 1Z4, Canada \\ ${ }^{2}$ National Institute of Polar Research, 1-9-10 Kaga, Itabashi, Tokyo 173-8515, Japan \\ ${ }^{3}$ Present address: Sea Mammal Research Unit, Gatty Marine Laboratory, University of St Andrews, St Andrews, Fife KY16 8LB, UK
}

\begin{abstract}
Changes in buoyancy due to seasonal or abnormal changes in body composition are thought to significantly affect the energy budget of marine mammals through changes in diving costs. We assessed how changes in body composition might alter the foraging efficiency of Steller sea lions Eumetopias jubatus by artificially adjusting the buoyancy of trained individuals. PVC tubes were attached to harnesses worn by Steller sea lions that had been trained to feed at fixed depths (10 to $30 \mathrm{~m}$ ) and to resurface inside a metabolic dome. Buoyancy was altered to simulate the naturally occurring differences in body composition reported in adult females ( 12 to $26 \%$ subcutaneous fat). Diving characteristics (transit times and time at depth) and aerobic energy expenditure (gas exchange) were measured. We found that foraging cost decreased with the duration of the dive and increased with dive depth. However, changes in body composition did not affect the diving metabolic rate of Steller sea lions for dives between 10 and $30 \mathrm{~m}$. We propose that Steller sea lions may adjust their diving lung volume to compensate for changes in buoyancy to avoid additional metabolic costs.
\end{abstract}

KEY WORDS: Body composition · Diving physiology $\cdot$ Marine mammal $\cdot$ Diving lung volume

\section{INTRODUCTION}

Marine birds and mammals spend considerable time (>50\%) underwater during foraging trips and must optimize the physiological effects of conflicting demands. Most notably, they must maximize the time they spend at a prey patch to increase prey acquisition while minimizing the time they spend on the surface to exchange metabolic gases.

Diving birds and mammals have developed sophisticated physiological processes to increase the depths they can attain and prolong the time they can spend underwater. For example, animals may conserve oxygen and thereby increase foraging times by reducing or terminating certain physiological processes while diving to increase the aerobic dive duration (DD) (digestion and thermoregulation; Zapol et al. 1979, Crocker et al. 1997, Schmidt et al. 2006). Metabolic costs of diving may also be reduced by reducing periph- eral blood flow and by using thick subcutaneous fat to limit heat loss in water. Increasing total body fat (body composition) reduces the thermal challenge posed by cold water and serves as a reserve for future energetic challenges. However, increased subcutaneous fat also increases buoyancy, which may in turn affect the metabolic cost of ascending, descending and staying at depth - thereby increasing the costs of foraging. Alternatively, diving animals may increase their metabolic rate using physiological (shivering) or behavioural processes (increased activity) to compensate for increased heat loss in water (Kvadsheim et al. 2005, Bostrom \& Jones 2007). While logic suggests that increasing metabolism $\left(\mathrm{O}_{2}\right.$ consumption rate $)$ to cover thermoregulatory needs will reduce aerobic DD (Rosen et al. 2007), no study has assessed this in foraging marine mammals. In fasting king penguins (Fahlman et al. 2005), complex changes in metabolic and thermoregulatory processes were observed, and it is possible that 
marine mammals exhibit similar plasticity in their thermoregulatory ability.

The relationship between buoyancy, diving behaviour and energetics is complicated. An animal that is positively buoyant at the surface will have to swim actively to depth, but will be aided by the buoyant lift during ascent. Variation in diving behaviour, supposedly related to differences in body composition, has been previously documented in wild pinnipeds (Webb et al. 1998, Beck et al. 2000, Watanabe et al. 2006). In grey seals, for example, both descent and ascent rates increased with increasing negative buoyancy, while DD and surface interval (SI) duration remained unchanged (Beck et al. 2000). However, in northern elephant seals, buoyancy was negatively correlated with descent rate, but did not affect the ascent rate (Webb et al. 1998).

Whether or not altered buoyancy and its concurrent effect on underwater swimming behaviour have energetic consequences in otariids is not known. Sato et al. (2002) showed that the inhaled air volume before a dive correlated with the dive depth in penguins, presumably a strategy to adjust buoyancy according to the depth of the dive. As lung capacities of marine mammals are generally larger than those of terrestrial mammals, Kooyman suggested that adjustment of lung volume provides a useful way to alter buoyancy (Kooyman 1973). Consequently, marine mammals could adjust their diving lung volume to compensate for changes in buoyancy - a strategy that would be particularly useful during shallow dives. Alternatively, the additional cost incurred by descending with additional buoyancy may equal the energetic saving reaped during ascent, and vice versa. For this reason, it is important to assess diving costs in animals with simulated variation in buoyancy to understand how changes in body composition may affect foraging costs and ultimately survival.

Body composition of female Steller sea lions Eumetopias jubatus varies seasonally (Pitcher et al. 2000). They are known to have the highest percentage body fat (and hence buoyancy) in the spring, before the summer pupping season, and are leanest in the fall. However, sea lions may also experience unpredictable changes in body composition induced by negative environmental changes that affect rates of energy expenditure (e.g. inclement weather, dispersed and difficult to find prey) or energy intake (e.g. reduced quality or quantity of prey). Changes in body composition will affect the foraging abilities of adult females, and will also have implications for the growth and survival of offspring (Iverson et al. 1993).

Changes in body composition affect a number of physiological and behavioural processes (scope of thermoregulation, reduction in metabolic rate, activity levels). We focused on one aspect of body composition (buoyancy) and examined how it affects energy expenditure (metabolism) during shallow dives. However, we wanted to measure only the effect of changes in buoyancy in the absence of other physiological changes that would have occurred if lipid composition were artificially altered (i.e. thermoregulation, metabolic depression, etc.). We therefore measured the metabolic rates of Steller sea lions that were trained to dive while carrying buoyancy tubes, and adjusted buoyancy to assess the possible consequence for wild animals that experience changes in body composition.

\section{MATERIALS AND METHODS}

All experiments were conducted under permits from Animal Care Committees of the University of British Columbia and the Vancouver Aquarium.

Sea lions. Experiments were conducted between April 26 and June 21, 2006 with 3 female Steller sea lions Eumetopias jubatus housed in a specially designed floating pen located in a coastal inlet in British Columbia, Canada. The sea lions freely chose to cooperate with all data collection and were never restrained or confined during any of the experimental trials. Two of the sea lions (F97HA and F97SI) were 9 yr old, and the third was 6 yr old (F00BO). Body mass of each sea lion was measured on a daily basis and averaged $( \pm \mathrm{SD}) 170.2 \pm 1.8 \mathrm{~kg}$ for F97HA $(\mathrm{n}=14), 211.6 \pm$ $1.3 \mathrm{~kg}$ for F97SI $(\mathrm{n}=16)$ and $135.7 \pm 0.8 \mathrm{~kg}$ for F00BO (n = 13).

Body composition, buoyancy and buoyancy adjustment. Total body water (TBW) was estimated once midway through the trial (mid-May) using the deuterium dilution method. TBW values were reduced by $4 \%$ to correct for overestimation by this method (Nagy \& Costa 1980). Total body lipid mass (TBL, kg) was determined from the predictive equation reported for Antarctic fur seals (Arnould 1995). The proportions of TBL and TBW were used to estimate the buoyancy of each animal from Eq. (2) in Webb et al. (1998). Buoyancy was adjusted to simulate the maximal naturally occurring differences in body composition, or the level of lipid mass, reported in adult female Steller sea lions ( $\sim 26$ to $\sim 12 \%$ subcutaneous fat, age 6 to 9 yr; Fig. 3 in Pitcher et al. 2000, see Table 1). Buoyancy was adjusted by attaching 2 matched PVC tubes (diameter: $7.5 \mathrm{~cm}$, length: $30 \mathrm{~cm}$ ) of various buoyancies to the harnesses routinely worn by the sea lions during openwater sessions. For positive buoyancy $(\mathrm{B}+)$ trials, the tube was closed off at both ends and the internal air volume was adjusted to result in an overall buoyancy that represented the upper limit of subcutaneous fat $(27 \%)$. Each tube gave a maximum B+ of 12.7 N. For 
Table 1. Eumetopias jubatus. Body mass $\left(M_{\mathrm{b}}\right)$, total body lipid (TBL), initial (B), positive (B+) and negative (B-) buoyancy, resting metabolic rate in water $\left(\mathrm{RMR}_{\mathrm{H}_{2} \mathrm{O}}\right.$ mean $\left.\pm \mathrm{SD}\right)$ and estimated diving lung volume (DLV; Kooyman \& Ponganis 1998). Values within parentheses are estimated TBL after buoyancy adjustment. Superscripted values are number of observations. Mean: values \pm SD

\begin{tabular}{|lccccccc|}
\hline Sea lion & $M_{\mathrm{b}}(\mathrm{kg})$ & TBL $(\%)$ & $\mathrm{B}(\mathrm{N})$ & $\mathrm{B}+(\mathrm{N})$ & $\mathrm{B}-(\mathrm{N})$ & $\mathrm{RMR}_{\mathrm{H}_{2} \mathrm{O}}\left(\mathrm{l} \mathrm{O}_{2} \mathrm{~min}^{-1}\right)$ & $\mathrm{DLV}(\mathrm{l})$ \\
\hline F97SI & 213.2 & 17.7 & -86.1 & $-62.4(24 \%)$ & $-100.6(12 \%)$ & $1.98 \pm 0.25^{16}$ & 7.5 \\
F97HA & 168.8 & 18.2 & -65.1 & $-43.5(26 \%)$ & $-81.8(12 \%)$ & $1.63 \pm 0.29^{14}$ & 5.9 \\
F00BO & 135.0 & 18.8 & -50.8 & $-33.1(27 \%)$ & $-63.6(13 \%)$ & $1.34 \pm 0.22^{14}$ & 4.7 \\
Mean & $172.3 \pm 39.2$ & $18.2 \pm 0.6$ & $-67.3 \pm 17.8$ & $-46.3 \pm 14.9$ & $-82.0 \pm 18.5$ & $1.30 \pm 0.16^{3}$ & $6.0 \pm 1.4$ \\
\hline
\end{tabular}

neutral (B, control) buoyancy, holes were drilled in the tubes to allow them to fill with water. For negative buoyancy (B-), holes were drilled, and the tubes were filled with a sheet of lead that represented a change in buoyancy equal to the lower range of subcutaneous fat of female adult Steller sea lions (Table 1; Pitcher et al. 2000). Holes in the B and B-tubes were drilled at the rear end of the tube to avoid changes in drag between compositions.

Experimental procedure and measurement of diving oxygen consumption. All experimental trials were performed in the morning, at least $16 \mathrm{~h}$ postprandial. Prior to the daily trials, each sea lion was weighed $( \pm 0.1 \mathrm{~kg})$ and fitted with a discrete webbing body harness that held the buoyancy tubes and a VHF transmitter (used to locate the sea lion in the event of it swimming out of the trial area). The animals were transported in a specially modified $6.7 \mathrm{~m}$ boat from their holding pen to the trial areas, where they dove from a floating respirometry dome to an underwater feeding tube placed at a predetermined depth (see below). A second $6.7 \mathrm{~m}$ research boat carrying the respirometry equipment and towing a floating barge was anchored in the trial area. The barge contained a rectangular hole through which a cage $(152 \times 152 \mathrm{~cm})$ was placed in the water. The cage opened at the bottom and allowed the sea lion to enter and breathe at the top. The cage made it possible to contain the sea lion under behavioural control for short periods of time to measure resting metabolic rate (RMR).

A transparent Plexiglas dome (200 1 internal volume) was placed above the cage enabling collection of respiratory gases. The system was built as a flow-through respirometer system, allowing determination of $\mathrm{O}_{2}$ and $\mathrm{CO}_{2}$ consumption rates $\left(\dot{V}_{\mathrm{O}_{2}}\right.$ and $\left.\dot{V}_{\mathrm{CO}_{2}}\right)$, respectively. A mass flow meter (Flow Kit Model $500 \mathrm{H}$, Sable Systems International) pulled $475 \mathrm{l} \mathrm{min}^{-1}$ through the dome. This mass flow meter automatically corrected flow rates to standard temperature and pressure (STP) despite variations in ambient temperature and barometric pressure. A subsample of this gas was passed via a canister of anhydrous $\mathrm{CaSO}_{4}$ (W. A. Hammond Drierite) to a paramagnetic $\mathrm{O}_{2}\left(\mathrm{FC}-1 \mathrm{~B} \mathrm{O}_{2}\right.$, Sable Systems International) and an infrared $\mathrm{CO}_{2}$ analyzer (CA-
1B, Sable Systems International). Data were sampled at $2 \mathrm{~Hz}$ and saved to a laptop.

The gas analyzers were calibrated before and after each experiment using ambient air $\left(20.9 \% \mathrm{O}_{2}\right)$ and $0.5 \% \mathrm{CO}_{2}$ in $\mathrm{N}_{2}$ from a commercial mixture (Praxair). Temperature $\left({ }^{\circ} \mathrm{C}\right)$ and humidity (\%) of the excurrent gas were measured using a commercial sensor (Springfield Precise Temp). Average respirometer temperature was $20.8 \pm 3.6^{\circ} \mathrm{C}$ (range: 11.5 to $28.9^{\circ} \mathrm{C}$ ), humidity was $51 \pm 13 \%$ (range: 27 to $80 \%$ ) and barometric pressure was $102.0 \pm 0.5 \mathrm{kPa}$ (range: 101.0 to $103.3 \mathrm{kPa}$ ). Humidity and temperature of the excurrent air made it possible to correct flow to standard pressure dry (STPD).

The accuracy of the respirometry system was determined by simultaneous $\mathrm{N}_{2}$ - and $\mathrm{CO}_{2}$-dilution tests (Fedak et al. 1981, Fahlman et al. 2005), and showed that the difference between the observed and expected values were within $4 \%$. Addition of $\mathrm{CO}_{2}$ confirmed that minimal amounts of $\mathrm{CO}_{2}$ were lost through dissolution in the seawater. The effective volume of the system was 2201 , including the volume of the respirometer and the plastic hose to the analyzers. With a flow rate of $4751 \mathrm{~min}^{-1}$, this gave a time constant of $0.46 \mathrm{~min}$. The time required to reach a $95 \%$ fractional transformation to a new steady state was 3.2 times the time constant, or 1.5 min (Fahlman et al. 2004).

A tube and pump system allowed delivery of fish (previously frozen herring) to various depths at different rates ( 0 to 12 fish min $^{-1}$ ) that simulated the animal reaching food patches of varying densities. For a dive trial, the sea lion was instructed to enter the respirometry dome and the cage door was closed. The animal stayed in the dome for $6 \mathrm{~min}$ to measure RMR. The duration was extended if steady values of $\mathrm{O}_{2}$ and $\mathrm{CO}_{2}$ were not recorded during the last $2 \mathrm{~min}$ of this period. The sea lion was then instructed to swim to the end of the feeding tube that was placed at a predetermined depth $(10,15,20$, or $30 \mathrm{~m})$. From this time until the end of the trial the animal received no further instructions from the trainer and diving continued at the sea lions' own volition.

Between 4 and 8 dives were carried out during each trial $\left(1\right.$ trial $\left.\mathrm{d}^{-1}\right)$, with durations of individual dives and 
surface intervals determined by the sea lion. For each dive, the fish delivery rate was varied in a randomized order which was determined before the start of the trial. To ensure that the sea lions were not naïve to the required dive parameters during a trial, each animal was trained at each depth and duration for 5 to $7 \mathrm{~d}$ prior to collecting any data. After the last dive, the sea lions remained in the dome until the $\mathrm{O}_{2}$ and $\mathrm{CO}_{2}$ levels had returned to pre-dive levels. This allowed measurement of the recovery period from the dive bout. A total of 43 dive trials were completed of which 24 were to $10 \mathrm{~m}$ (sea lions: F97SI, F00BO, F97HA), 3 were to $15 \mathrm{~m}$ (F97SI), 3 were to $20 \mathrm{~m}$ (F97SI) and 13 were to $30 \mathrm{~m}$ (F97HA, F00BO). The order of trials (depth and buoyancy group) was randomized to offset any potential confounding effects of changes in body composition over the duration of the experiment. The water temperatures at the surface and at the end of the feeding tube were monitored during each trial using remote temperature loggers (Onset Computer). Temperatures at the surface ranged from 10.0 to $17.0^{\circ} \mathrm{C}$, while temperatures at depth ranged from 9.0 to $11.2^{\circ} \mathrm{C}$.

The average $\dot{V}_{\mathrm{O}_{2}}$ for each dive and subsequent surface interval (1 dive event) was estimated by integrating the instantaneous oxygen consumption rate (Bartholomew et al. 1981) over the entire post-dive surface interval and dividing this by the dive cycle duration (Scholander 1940, Fahlman et al. 2008). All SI in a dive series, except the last, were $<30 \mathrm{~s}$. For the last dive cycle, the sea lion spent longer at the surface during which time $\mathrm{O}_{2}$ consumption returned to pre-dive resting levels. Therefore, only dives with $\mathrm{SI}<30$ s were used in the analysis to estimate the metabolic rate of a dive event (DMR).

To account for differences in body mass, $\dot{V}_{\mathrm{O}_{2}}$ was converted to mass-corrected metabolic rate $\left(\mathrm{s} \dot{\mathrm{O}}_{\mathrm{O}_{2}}\right)$ using the previously predicted mass exponent for Steller sea lions (body mass ${ }^{0.6}$; McPhee et al. 2003).

Data assessment and statistical analysis. Mixedmodel regression techniques were used to determine the best predictive model for the relationship between $\dot{V}_{\mathrm{O}_{2}}$ (dependent variable) and 4 experimental variables (treatment group, DD, dive depth, body mass) as independent fixed covariates. Initially, a univariate analysis on each independent variable was performed, and only those variables with $\mathrm{p}<0.20$ (Wald's tests) were considered in the multivariate analysis. Stepwise techniques were used to search for the best model. The likelihood ratio test was used to determine significance of parameters between nested models. In this test, significance was defined by increases in the loglikelihood (LL) values of the models (i.e. significantly smaller negative LL values). The models were analyzed and corrected for outliers and departures from normality and linearity. Statistical analyses were performed using S-plus 2000 (Lucent Technologies). Acceptance of significance was set at $p<0.05$, and $0.05<\mathrm{p}<0.1$ was considered to be important enough to warrant investigation or consideration.

\section{RESULTS}

\section{Dive duration and surface interval}

DD (min) and SI (min) of Steller sea lions were positively correlated for all animals $(p<0.01)$, but there were significant differences in slopes and intercepts between animals ( $\mathrm{p}<0.01$, ANCOVA). A mixedeffects ANOVA, using animal as a random factor, resulted in the following predictive equation:

$$
\mathrm{SI}=0.094+0.120 \times \mathrm{DD}
$$

In addition, DD increased linearly with dive depth ( $\mathrm{p}$ $<0.01$, mixed-model ANOVA), but the slopes differed between animals $(\mathrm{p}<0.01$, ANCOVA). The prediction equation from the mixed-model ANOVA was:

$$
\mathrm{DD}=0.67+0.059 \times \text { depth }
$$

\section{Rate of oxygen consumption}

Mean RMR in water increased proportionally with body mass (kg) (Fig. 1) between individuals. The minimum and maximum RMRs observed were 1.09 and $2.58 \mathrm{I} \mathrm{O}_{2} \mathrm{~min}^{-1}$, respectively. Mean $( \pm \mathrm{SEM})$ respiratory exchange ratio $($ RER) was $0.87 \pm 0.04$, and individual

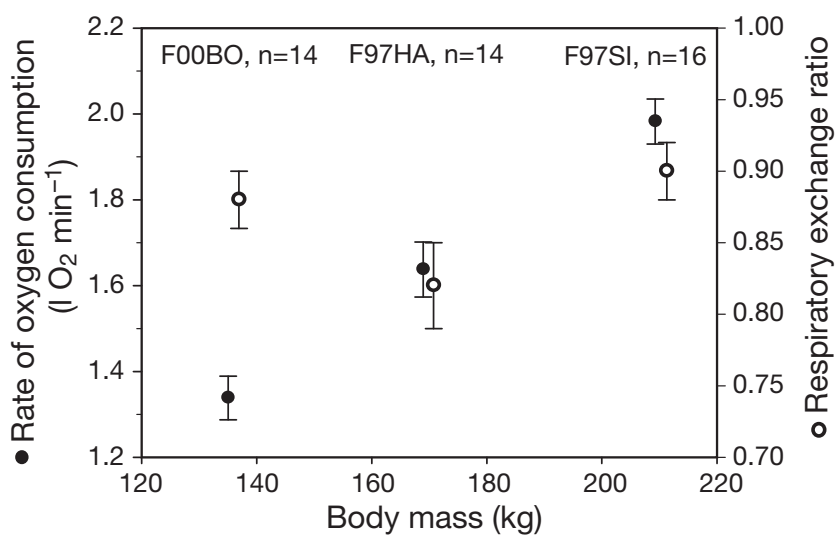

Fig. 1. Eumetopias jubatus. Relationship between body mass and in-water resting rate of oxygen consumption $\left(\dot{V}_{\mathrm{O}_{2}}\right.$ closed circles) or respiratory exchange ratio (RER, open circles) for 3 Steller sea lions (F97SI, F97HA, F00BO). Values are means $( \pm$ SEM) for each individual, with ID and number $(n)$ of measurements indicated above each mean value. Values for body mass are slightly offset for RER to improve visual representation 
mean values ranged between 0.82 and 0.90 (Fig. 1). There were no systematic changes in RER with depth or buoyancy.

There was a systematic change in DMR with repeated dives $(p<0.01)$, where the first dive had a significantly lower DMR and the last dive had a significantly higher DMR than all other dives. However, no changes in DMR were noted between the intervening dives. We therefore removed the first and last dive for the remainder of the analysis.

DMR (both $\dot{V}_{\mathrm{O}_{2}}$ and $\mathrm{s} \dot{\mathrm{V}}_{2}$ ) decayed exponentially with DD (Fig. 2). Metabolic rates for dives lasting $<2 \mathrm{~min}$ had the highest variability, ranging between 0.36 and $4.81 \mathrm{O}_{2} \mathrm{~min}^{-1}$. In contrast, DDs $>2$ min showed much less variability (Fig. 2A).

Buoyancy had no effect on DMR ( $p>0.1$, repeatedmeasures ANOVA; Fig. 3). However, we found that average DMR $\left(\mathrm{l} \mathrm{O}_{2} \mathrm{~min}^{-1}\right)$ decreased with depth from $10 \mathrm{~m}\left(1.98 \pm 0.07 \mathrm{l} \mathrm{O}_{2} \mathrm{~min}^{-1}\right.$, mean $\left.\pm \mathrm{SEM}\right)$ to $30 \mathrm{~m}$ $\left(1.54 \pm 0.051 \mathrm{O}_{2} \mathrm{~min}^{-1} ;\right.$ Fig. 4). Diving $\dot{V}_{\mathrm{O}_{2}}$ in the animal (F97SI) diving to $15 \mathrm{~m}\left(2.41 \pm 0.221 \mathrm{O}_{2} \mathrm{~min}^{-1}\right)$ and $20 \mathrm{~m}$ $\left(2.36 \pm 0.25 \mathrm{l} \mathrm{O}_{2} \mathrm{~min}^{-1}\right)$ was not different from that at
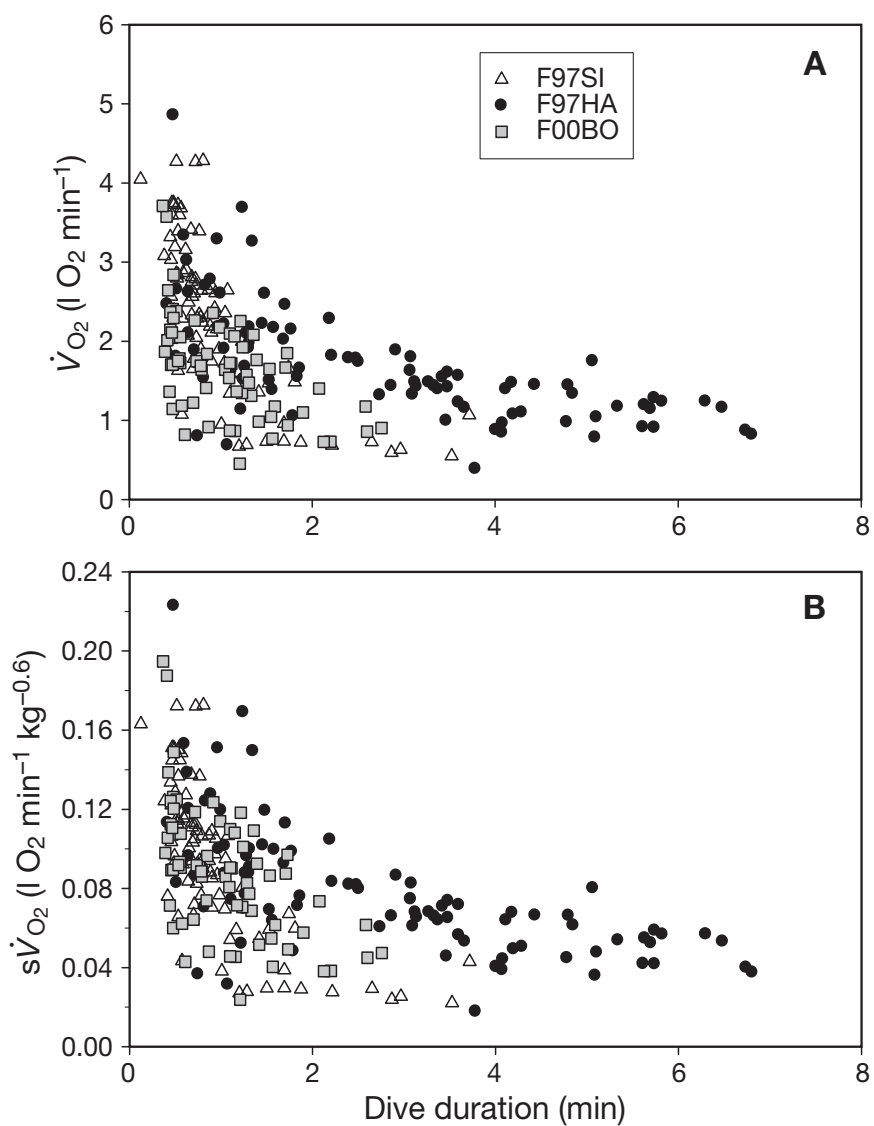

Fig. 2. Eumetopias jubatus. Dive duration versus (A) wholeanimal diving metabolic rate $\dot{V}_{\mathrm{O}_{2}}$ and (B) mass-corrected diving metabolic rate $\left(\mathrm{s} \dot{\mathrm{O}}_{2}\right.$ ) for 3 female Steller sea lions (F97SI, F97HA, F00BO) diving to 10, 15, 20, or $30 \mathrm{~m}$

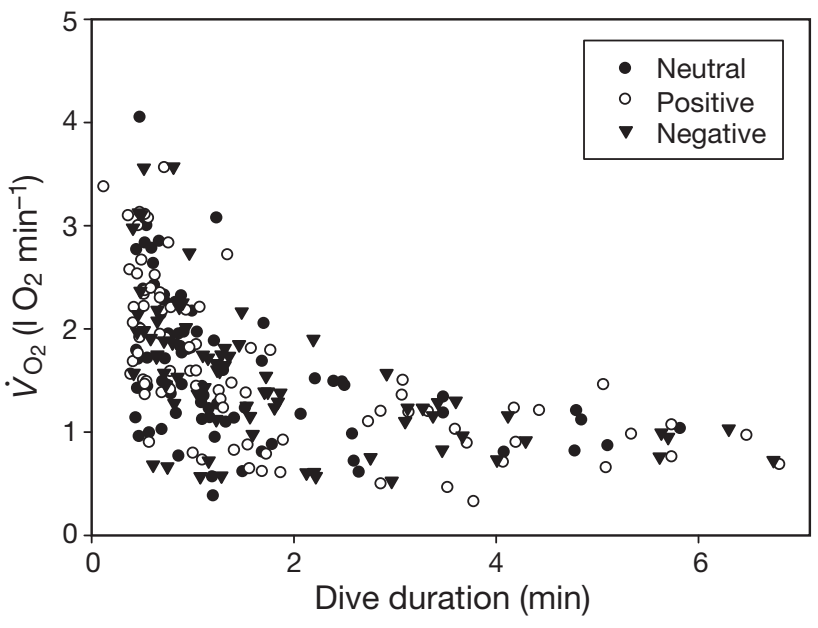

Fig. 3. Eumetopias jubatus. Dive duration versus wholeanimal diving metabolic rate $\left(\dot{V}_{\mathrm{O}_{2}}\right)$ for 3 female Steller sea lions (F97SI, F97HA, F00BO) for neutral, positive and negative buoyancy compositions

$10 \mathrm{~m}$. Similarly, $\mathrm{s} \dot{\mathrm{O}}_{2}\left(\mathrm{l} \mathrm{O}_{2} \mathrm{~min}^{-1} \mathrm{~kg}^{-0.6}\right)$ decreased from $10 \mathrm{~m}\left(88.4 \mathrm{ml} \mathrm{O}_{2} \mathrm{~min}^{-1} \mathrm{~kg}^{-0.6}\right)$ to $30 \mathrm{~m}\left(75.4 \mathrm{ml} \mathrm{O}_{2} \mathrm{~min}^{-1}\right.$ $\mathrm{kg}^{-0.6} ;$ Fig. 2B). There was no difference in $\mathrm{s} \dot{\mathrm{O}}_{\mathrm{O}_{2}}$ at 10 , $15\left(97.3 \mathrm{ml} \mathrm{O}_{2} \mathrm{~min}^{-1} \mathrm{~kg}^{-0.6}\right)$, or $20 \mathrm{~m}\left(95.4 \mathrm{ml} \mathrm{O}_{2} \mathrm{~min}^{-1}\right.$ $\mathrm{kg}^{-0.6}$ ) for F97SI.

Deeper dives generally lasted longer than shallower dives (Eq. 2). Within and between sea lions, DD increased as depth increased $(p<0.01)$, while buoyancy did not affect DD at any depth ( $p>0.1$, repeatedmeasures ANOVA).

Linearizing the relationship between $\mathrm{s} \dot{\mathrm{O}}_{2}$ and DD data using a negative exponential function revealed significant differences in both the slope $(p<0.01$, ANCOVA) and intercept $(p<0.01)$ between animals.

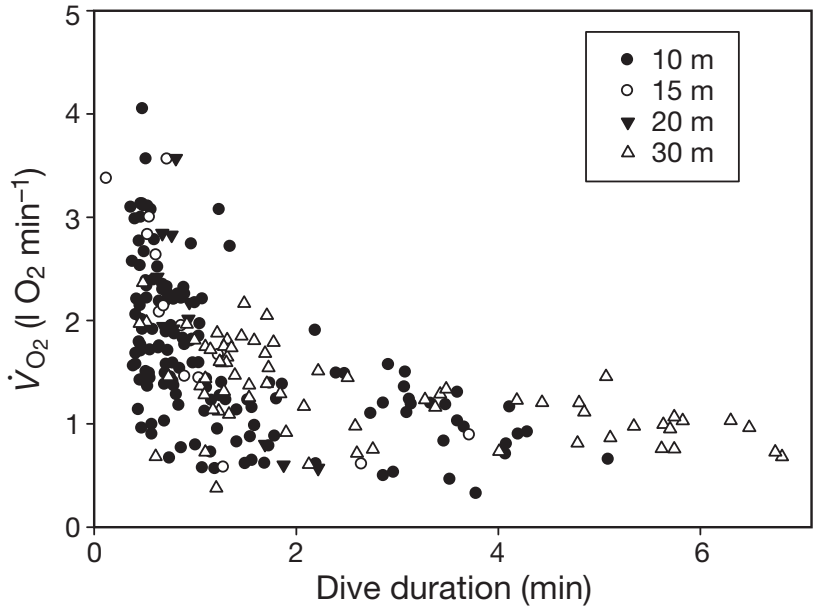

Fig. 4. Eumetopias jubatus. Dive duration versus wholeanimal diving metabolic rate $\left(\dot{V}_{\mathrm{O}_{2}}\right)$ for 3 female Steller sea lions (F97SI, F97HA, F00BO) for dives to 10, 15, 20 and $30 \mathrm{~m}$ 
Given the potential interaction between DD and dive depth on calculations of metabolic costs, both variables were considered together. The best mixed-model ANOVA suggested that both depth and DD were significant covariates $(p<0.01)$, while adjustment of buoyancy $(\mathrm{p}>0.2)$ did not affect DMR. The best model for $\mathrm{s} \dot{V}_{\mathrm{O}_{2}}$ was:

$\mathrm{s} \dot{\mathrm{V}}_{\mathrm{O} 2}=0.172-0.148 \times\left(1-\mathrm{e}^{(-\mathrm{DD})}\right)+0.000867 \times$ depth

\section{DISCUSSION}

Our objective was to determine if acute changes in body composition (buoyancy) affected foraging cost in captive female Steller sea lions. Our experimental design allowed us to test animals diving to depths up to $30 \mathrm{~m}$, which was within the dive range most commonly observed in adult female Steller sea lions in the wild throughout the year (Merrick \& Loughlin 1997); thus, our data are particularly relevant for this age class and species. We reasoned that buoyancy adjustment could potentially have a small effect on DMR, and allowed the animals to repeatedly dive to amplify any differences. While buoyancy did not affect DMR, our data suggest that when both DD and depth are considered together, diving deeper increases metabolic cost (for dives of similar durations; Fig. 4).

Studies with wild seals and birds have detected behavioural differences related to artificial changes in buoyancy (Webb et al. 1998, Watanabe et al. 2006, Elliott et al. 2007). In northern elephant seals, there was a negative correlation between buoyancy and descent rate. However, DD, surface interval, or ascent rate did not change (Webb et al. 1998). In thick-billed murres, adjustment of buoyancy or drag significantly reduced DD and descent rate (Elliott et al. 2007). We were therefore surprised that the metabolic rate of our sea lions did not differ between treatments over a dive event.

The much larger natural changes that occur within the adipose tissue of phocids (Webb et al. 1998) compared to Steller sea lions (Pitcher et al. 2000) may explain why studies in seals have detected differences in dive behaviour, while we did not observe any differences in DMR for sea lions within the range of imposed changes in buoyancy. It is also possible that the metabolic savings associated with gliding are only significant for dives deeper than $30 \mathrm{~m}$, especially as buoyancy changes caused by compression of the lower respiratory system exponentially decrease with dive depth (Bostrom et al. 2008). It may also be that changes in behaviour are insufficient alone to explain differences in DMR.

We suspect the sea lions in our study might have compensated for the buoyancy effect of the tubes by adjusting their dive lung volume, similar to that seen in king penguins (Sato et al. 2002), which could explain why metabolic costs did not change. Steller sea lions inhale before diving, while phocid seals generally exhale. All of the sea lions in our study were negatively buoyant for all 3 treatments (not accounting for the air in the respiratory system; Table 1). If the sea lions dove with maximal lung volumes similar to those of California sea lions ( $55 \mathrm{ml} \mathrm{kg}^{-1}$; Lenfant et al. 1970), the buoyancy would have increased between 72 and $115 \mathrm{~N}$. Thus, by diving on maximal inhalation the sea lions would have been nearly neutrally buoyant, while carrying the negatively buoyant tubes. A reduction in the diving lung volume by approximately $2 \mathrm{l}$ for the neutrally buoyant tubes and an additional 21 for the positively buoyant tubes would have effectively compensated for the changes in buoyancy between experimental treatments. Thus, it is possible that the Steller sea lions adjusted inhalation volume to offset the effects of the tubes, which in turn would affect total body $\mathrm{O}_{2}$ store and potentially the aerobic DD.

All dives but one were within the calculated aerobic dive limit (range: 2.8 to $5.6 \mathrm{~min}$ ) of our study animals, assuming a total body $\mathrm{O}_{2}$ store of $40.4 \mathrm{ml} \mathrm{O}_{2} \mathrm{~kg}^{-1}$ for an adult female Steller sea lion, including a dive lung volume of $55 \mathrm{ml} \mathrm{kg}^{-1}$ (Richmond et al. 2006) and using the estimated metabolic rate for each dive event as a measure of the dive metabolic rate. Even when assuming the sea lions decreased their lung storage compositions, our calculations show it was theoretically possible for them to have done so and remained within the aerobic dive limit. It is therefore reasonable to hypothesize that the sea lions in our study compensated for changes in buoyancy by adjusting their inhaled diving lung volume, which fits with the prediction made by Kooyman (1973).

Intermittent propulsion and gliding may help reduce the cost of transport and thereby overall metabolic rate during the dive in Weddell seals and bottlenose dolphins (Williams 2001). This metabolic sparing technique requires the animal to actively swim to a depth where they become neutrally buoyant. This is followed by passive gliding as the animal becomes increasingly negatively buoyant. Weddell seals glide during the last $10 \mathrm{~m}$ of descent to a maximum depth of $30 \mathrm{~m}$ (Williams 2001), with glide depth largely depending on the buoyancy of the animal (i.e. the proportion of adipose tissue and the total volume of air in the respiratory system and fur).

Steller sea lions appear to swim actively during the entire ascent, but only during the first $5 \mathrm{~m}$ of descentafter which they glide passively (Fahlman et al. 2008). Sea lions feeding at an artificial prey patch exerted limited energy as fish pieces were delivered to a single location (Fahlman et al. 2008). Changes in buoyancy 
mostly affect the metabolic cost of active swimming by increasing the necessary power input for upward or downward movement. The fact that the active phase comprised only a relatively small proportion of the entire dive could explain why there were no differences in DMR between the buoyancy treatments. In addition, adjustment of diving lung volumes to compensate for changes in buoyancy may be effective up to $30 \mathrm{~m}$, but not for species that dive much deeper, which may explain why studies in deep-diving elephant seals reported alterations in dive behaviour (Webb et al. 1998).

In fur seals, Boyd et al. (1997) showed that increased drag altered the angle of descent to compensate for the slower swimming speed. It is possible that the sea lions made similar alterations in their underwater swimming behaviour to reduce energy cost in the various treatment groups. Steller sea lions are naturally negatively buoyant at the beginning of a dive and are therefore able to glide during most of the descent (Fahlman et al. 2008). However, a negatively buoyant animal that glides during a portion of the descent will be forced to swim actively during ascent (or vice versa), and will incur an overall metabolic cost for the dive that depends on the relative costs and savings of these activities. If the metabolic savings for a negatively buoyant animal during descent equals the additional cost of active swimming during ascent, relatively small changes in buoyancy-as seen in Steller sea lionsmay not result in significant differences in net metabolic cost. This scenario appears likely, based on previous experiments that showed the metabolic sparing gained by sea lions gliding to depth equalled the additional cost of active swimming to the surface (Fahlman et al. 2008). Unfortunately, we were unable to record acceleration during our buoyancy study to assess these changes. However, both changes in swimming behaviour and metabolic costs should be addressed in future studies.

One problem with our experimental approach was that sequential dives could have potentially affected our estimated DMR. We did note a significant order effect, whereby the DMR of the first dive was significantly lower than that of subsequent dives, while the last dive had significantly higher rates than all other dives. Excluding these 2 dives from our analysis removed the order effect. Other studies have solved this problem by analyzing only those dives with postdive recovery periods long enough for $\dot{V}_{\mathrm{O}_{2}}$ to return to within $2 \%$ of the pre-dive resting rate (Williams et al. 2004). However, this fails to account for any sequential effect from preceding dives. Our experiments provide a qualitative comparison of the effects of buoyancy on metabolism between individuals, and yield conclusions that are strengthened by our experimental design that randomized buoyancy treatments between trials and animals. However, because of the systematic changes in estimated DMR with dive number, which we suggest is evidence of an incurred $\mathrm{O}_{2}$ debt, the metabolic rates we measured may not reflect the actual costs of diving and should not be used for quantitative purposes (A. Fahlman et al. unpubl. obs.).

It is possible that sufficient drag was created by the harness and buoyancy tubes to mask changes in metabolic cost attributable to buoyancy changes. The harness we used was similar to that used by Cornick et al. (2006), but without the Astroturf used to increase hydrodynamic drag. Given that the harness assemblage used in the previous study increased drag by $26 \%$, the additional drag caused just by our harness should therefore be significantly less. However, adding the buoyancy tubes did appear to increase hydrodynamic drag given that the metabolic cost of a dive event of a fixed duration was similar between all 3 buoyancy conditions, but greater than the (previously collected) metabolic cost for dives without buoyancy tubes or without the harness.

In summary, altering buoyancy within the narrow range seen in wild Steller sea lions did not affect DMR during dives between 10 and $30 \mathrm{~m}$. It is possible that the sea lions adjusted the inhaled air volume to counteract the changes in buoyancy. This would reduce the aerobic DD in negatively buoyant sea lions as compared to positively buoyant sea lions, and would possibly reduce foraging efficiency. This hypothesis should be tested in future studies and may shed further light on potential limitations in feeding success.

Acknowledgements. Funding was provided to the North Pacific Universities Marine Mammal Research Consortium by the North Pacific Marine Science Foundation and the National Oceanographic and Atmospheric Administration. We are also particularly grateful for the insightful comments of the referees and for the assistance from our research technicians (D. Gummeson, R. Marshall, J. Potter and R. MacVicar), animal trainers (V. Mercer, G. Shepherd, T. Neal, N. Waller and B. Lasby) and administrative staff at the Open Water Research Station and the Vancouver Aquarium.

\section{LITERATURE CITED}

Arnould JPY (1995) Indices of body condition and body composition in female Antarctic fur seals (Arctocephalus gazella). Mar Mamm Sci 11:301-313

Bartholomew GA, Vleck D, Vleck C (1981) Instantaneous measurements of oxygen consumption during pre-flight warm-up and post-flight cooling in sphingid and saturniid moths. J Exp Biol 90:17-32

> Beck CA, Bowen WD, Iverson SJ (2000) Seasonal changes in buoyancy and diving behaviour of adult grey seals. J Exp Biol 203:2323-2330

> Bostrom BL, Jones DR (2007) Exercise warms adult leatherback turtles. Comp Biochem Physiol A Mol Integr Physiol 
$147: 323-331$

Bostrom B, Fahlman A, Jones DR (2008) Tracheal compression delays alveolar collapse during deep diving in marine mammals. Resp Physiol Neurobiol 161:298-305

Boyd IL, McCafferty DJ, Walker TR (1997) Variation in foraging effort by lactating Antarctic fur seals: response to simulated increased foraging costs. Behav Ecol Sociobiol 40:135-144

Cornick LA, Inglis SD, Willis K, Horning M (2006) Effects of increased swimming costs on foraging behavior and efficiency of captive Steller sea lions: evidence for behavioral plasticity in the recovery phase of dives. J Exp Mar Biol Ecol 333:306-314

> Crocker DE, LeBoeuf BJ, Costa DP (1997) Drift diving in female northern elephant seals: implications for food processing. Can J Zool 75:27-39

Elliott KH, Davoren GK, Gaston AJ (2007) The influence of buoyancy and drag on the dive behaviour of an Arctic seabird, the thick-billed murre. Can J Zool 85:352-361

Fahlman A, Handrich Y, Woakes AJ, Bost CA, Holder R, Duchamp C, Butler PJ (2004) Effect of fasting on the $\dot{V}_{\mathrm{O}_{2}}$ and $\mathrm{fH}$ relationship in king penguins, Aptenodytes patagonicus. Am J Physiol Regul Integr Comp Physiol 287: R870-R877

Fahlman A, Schmidt A, Handrich Y, Woakes AJ, Butler PJ (2005) Metabolism and thermoregulation during fasting in king penguins, Aptenodytes patagonicus, in air and water. Am J Physiol Regul Integr Comp Physiol 289:R670-R679

Fahlman A, Wilson R, Svärd C, Rosen DAS, Trites AW (2008) Activity and diving metabolism correlate in Steller sea lion Eumetopias jubatus. Aquat Biol 2:75-84

> Fedak MA, Rome L, Seeherman HJ (1981) One-step $\mathrm{N}_{2}$ dilution technique for calibrating open-circuit $V_{\mathrm{O}_{2}}$ measuring systems. J Appl Physiol 51:772-776

Iverson SJ, Bowen WD, Boness DJ, Oftedal OT (1993) The effect of maternal size and milk energy output on pup growth in gray seals (Halichoerus grypus). Physiol Zool 66:61-88

Kooyman GL (1973) Repiratory adaptations in marine mammals. Am Zool 13:157-168

Kooyman GL, Ponganis PJ (1998) The physiological basis of diving to depth: birds and mammals. Annu Rev Physiol 60:19-32

Kvadsheim PH, Folkow LP, Blix AS (2005) Inhibition of shivering in hypothermic seals during diving. Am J Physiol Regul Integr Comp Physiol 289:R326-R331

Lenfant C, Johansen K, Torrance JD (1970) Gas transport and

Editorial responsibility: Peter Corkeron,

Woods Hole, Massachusetts, USA oxygen storage capacity in some pinnipeds and the sea otter. Respir Physiol 9:277-286

McPhee JM, Rosen DAS, Andrews RD, Trites AW (2003) Predicting metabolic rate from heart rate in juvenile Steller sea lions Eumetopias jubatus. J Exp Biol 206:1941-1951

Merrick RL, Loughlin TR (1997) Foraging behavior of adult female and young-of-the-year Steller sea lions in Alaskan waters. Can J Zool 75:776-786

Nagy K, Costa DP (1980) Water flux in animals: analysis of potential errors in the tritiated water technique. Am J Physiol 238:R454-R465

Pitcher KW, Calkins DG, Pendleton GW (2000) Steller sea lion body condition indices. Mar Mamm Sci 16:427-436

Richmond JP, Burns JM, Rea LD (2006) Ontogeny of total body oxygen stores and aerobic dive potential in Steller sea lions (Eumetopias jubatus). J Comp Physiol B 176: $535-545$

Rosen DA, Winship AJ, Hoopes LA (2007) Thermal and digestive constraints to foraging behaviour in marine mammals. Philos Trans R Soc Lond 362:2151-2168

- Sato K, Naito Y, Niizuma Y, Watanuki Y and others (2002) Buoyancy and maximal diving depth in penguins: Do they control inhaling air volume? J Exp Biol 205:1189-1197

Schmidt A, Alard F, Handrich Y (2006) Changes in body temperatures in king penguins at sea: The result of fine adjustments in peripheral heat loss? Am J Physiol Regul Integr Comp Physiol 291:R608-R618

Scholander PF (1940) Experimental investigations on the respiratory function in diving mammals and birds. Hval Skr 22:1-131

- Watanabe Y, Baranov EA, Sato K, Naito Y, Miyazaki N (2006) Body density affects stroke patterns in Baikal seals. J Exp Biol 209:3269-3280

- Webb PM, Crocker DE, Blackwell SB, Costa DP, Le Boeuf BJ (1998) Effects of buoyancy on the diving behavior of northern elephant seals. J Exp Biol 201:2349-2358

- Williams TM (2001) Intermittent swimming by mammals: a strategy for increasing energetic efficiency during diving. Am Zool 41:166-176

Williams TM, Fuiman LA, Horning M, Davis RW (2004) The cost of foraging by a marine predator, the Weddell seal Leptonychotes weddellii: pricing by the stroke. J Exp Biol 207:973-982

Zapol WM, Liggins GC, Schneider RC, Qvist J, Snider MT, Creasy RK, Hochachka PW (1979) Regional blood flow during simulated diving in the conscious Weddell seal. J Appl Physiol 47:968-973

Submitted: March 14, 2008; Accepted: June 16, 2008

Proofs received from author(s): July 25, 2008 